\title{
Soil Quality Status of Different Land-Use Types in Shiqu County, China
}

\author{
Wenju Liao ${ }^{1, a}$ Dehua Tang ${ }^{1, b}$ Xinggui Wang ${ }^{1, c}$ Xiaobin Cheng ${ }^{1, d}$ \\ ${ }^{1}$ College of Environment and Life Science, Sichuan Minzu College, Kangding, China \\ a e-mail:wenjuliao@126.com, ${ }^{\mathrm{b}} \mathrm{e}-\mathrm{mail}$ :dehuatang@126.com,

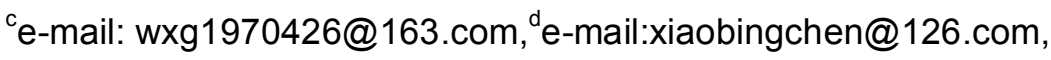

Keywords: Soil quality; Land-use; Soil property; Soil fertility

Abstract. The soil quality status of three typical land-use types (grassland, forestland and cultivated land) in Shiqu County is surveyed, including soil $\mathrm{pH}$, soil calcium carbonate, cation exchange capacity, organic matter, total nitrogen, total phosphorus, total potassium, available nitrogen, available phosphorus, available potassium and microelements levels. The soil quality of different land-use types is evaluated by the soil quality index. The investigation results indicate the different land-use types display significant differences in soil fertility, and the Shiqu County soil is serious lack of microelements. In addition, the soil quality index of different land-use types is in order of grassland $(73.2 \%)>$ forestland $(62.2 \%)>$ cultivated land $(27.1 \%)$.

\section{Introduction}

With the increasingly acute contradictions among the population, resource and environment, the soil quality issues are continuously concerned around the world [1]. Soil quality is defined as the "capacity of a soil to function, within ecosystems boundaries, to sustain biological productivity, improve environmental quality and support human and plant health" [2]. Soil physicochemical properties have varying impact degrees on the soil quality. As a result, the assessment of integrated soil quality indicators is on the basis of the average weighted contribution of each soil property, which may better quantify soil quality indicators for different land-use types $[3,4]$. Recently, the land-use type and its impact on soil quality have become research focuses at home and abroad $[5,6]$. The investigation of soil quality evolution process, characteristics and mechanisms under different land-use types and managements, is a basis for establishing the scientific soil quality control system and improving the land management level. In this study, we make an in-depth investigation of soil properties of different land-use types in Shiqu County, aiming at providing a scientific basis for the land development and management, environmental protection and soil restoration.

\section{Materials and Methods}

Study area. The study area is located in Ganzi Tibetan Autonomous Prefecture on the eastern Tibetan

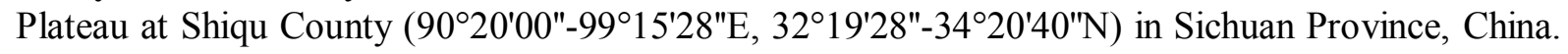
The main land-use type of the region is grassland (GL), whose soil area is 35.9271 million mu, accounting for $98.47 \%$ of the total area. In addition, the soil area of forestland (FL) is 0.5051 million $\mathrm{mu}(1.38 \%)$ and the cultivated land (CL) is 0.0518 million mu $(0.15 \%)$.

Selection and collection of soil samples. The CL samples were collected from the surface soil of $0-20 \mathrm{~cm}$ using auger replicated three times. The GL and FL soil samples were collected from profiles dug to a depth of $20-40 \mathrm{~cm}$. Each soil sample of the three land-use types was obtained by mixing the collected profile and other random five profiles around. The properties of soil samples were measured including soil $\mathrm{pH}$, soil calcium carbonate, cation exchange capacity, soil organic matter, total nitrogen, total phosphorus, total potassium, available nitrogen, available phosphorus, available potassium and microelements.

Analysis of soil samples. The soil samples collected from the field were air dried, lightly ground and passed through a 2-mm sieve prior to physicochemical analysis. At the time of sieving, roots and other debris were removed from the soil and discarded. Soil $\mathrm{pH}$ was determined in 1:1 soil-water slurry 
(Multiline F/SET-3, Germany). The organic matter content was measured by the drying method. Kjeldahl method was used for the determination of total nitrogen. The available nitrogen content was calculated by the titration with the standard solution. The total phosphorus and available phosphorus were obtained using spectrophotometer after $\mathrm{NaOH}$ digestion and sodium bicarbonate method, respectively. The measurements of total potassium and available potassium were using ICP-2070 (BAIRD, U.S.). The microelements $(\mathrm{Cu}, \mathrm{Zn}, \mathrm{Fe}, \mathrm{Mn})$ were extracted by diethylene triamine pentacetate acid, and then measured by ICP-OES method. The microelement B was extracted in boiling water, and measured by ICP-OES method.

Soil quality index. Soil quality index (SQI) reflects the relative quality of soils available under different land-use types. It is a useful tool to assess sustainability of soil resources that are managed and used in different land-use systems. In the work, soil density, $\mathrm{pH}$, organic matter, total nitrogen, total phosphorus, total potassium, available nitrogen, available phosphorus, and available potassium were chosen for the SQI[3,7].

$$
S Q I=\sum_{i}^{n} W_{i} \times Q_{i}
$$

Where $\mathrm{n}$ is the number of observations; Wi is the weight vector of ith soil quality factor; $\mathrm{Q}_{\mathrm{i}}$ is the member-membership value of each soil quality factor. $\mathrm{Q}_{i}$ was calculated by ascending or descending functions using the Equation 2 or Equation3, respectively. Based on appropriate ranges for individual soil properties favorable for plant growth and results of our laboratory analysis, the Equation 2 was adopted for nutrient factors such as oil $\mathrm{pH}$, organic matter, $\mathrm{N}, \mathrm{P}, \mathrm{K}$, and etc., while the Equation 3 was chosen for the calculation of soil density. The membership values of the selected soil quality factor were subjected to principal component analysis (PCA) to determine the weights for each soil indicator.

$$
\begin{aligned}
& Q_{i}=\left(X_{i}-X_{i, \min }\right) /\left(X_{i, \max }-X_{i, \text { min }}\right) . \\
& Q_{i}=\left(X_{i, \min }-X_{i}\right) /\left(X_{i, \text { max }}-X_{i, \text { min }}\right) .
\end{aligned}
$$

Where $\mathrm{X}_{\mathrm{i}}$ is the value of the soil physicochemical properties that were selected for the soil quality; $\mathrm{X}_{\mathrm{i}}$, max and $\mathrm{X}_{\mathrm{i}}$, min are the maximum and minimum value of ith soil property, respectively.

Usually, the weight vector $\mathrm{W}_{\mathrm{i}}$ was referred to the contribution of each factor on the soil quality. the weight vector $\mathrm{W}_{\mathrm{i}}$ was obtained by calculating the role of each factor in soil quality through the component capacity by PCA (Equation 4 ).

$$
W_{i}=C_{i} / \sum_{i}^{n} C_{i}
$$

Where $C_{i}$ is the component capacity score coefficient of soil quality factor i. Finally, SQI was calculated as a summed product of membership values $\mathrm{Q}_{i}$ and the weights of the selected soil quality indicators. To evaluate the soil quality under different land-use types, SQI was classified into five arbitrary classes as: (I) excellent (>0.80), (II ) good (0.60-0.80), (III) medium (0.40-0.60), (IV) poor $(0.20-0.40)$ and $(\mathrm{V})$ extremely poor $(<0.20)$.

\section{Results and Discussion}

Soil pH. Soil pH makes great influence on soil fertility and plant growth. Table 1 lists the soil $\mathrm{pH}$ of different land-use types.

Table 1. The soil $\mathrm{pH}$ of different land-use types

\begin{tabular}{llll}
\hline $\mathrm{pH}$ & GL, $10000 \mathrm{mu}$ & FL, $10000 \mathrm{mu}$ & CL, $10000 \mathrm{mu}$ \\
\hline $5.5-6.5$ & 839.7 & 0 & 0 \\
$6.5-7.5$ & 1663.64 & 0 & 0 \\
$7.5-8.5$ & 1089.37 & 50.51 & 5.1801 \\
\hline
\end{tabular}

The soil pH of FL and CL soils are higher than that of GL soil. The soil of Shiqu County is majority of neutral and slightly acidic soils. That because the majority of the county soil $\mathrm{pH}$ was suitable for plant growth, but the slightly alkaline soil had a certain impact on the growth of crops and plants, which 
was mainly in the two aspects. First, it affected the availability of nutrients in the soil. There were great many of calcium and magnesium components in the slightly alkaline soil, and they reacted with phosphorus compounds to generate insoluble precipitates. So, fertilizing phosphates appropriately was very important for the enhancement of crop yields in the slightly alkaline soil. Secondly, it affected the seedling growth of alpine species such as fir and spruce which were suitable for growing in the acidic soil environment. Such problems encountered in the production practice, for example, the growth of woods was very poor due to the slightly alkaline soil of FL soil.

Soil calcium carbonate. Soil calcium carbonate content could fully reflect the county's soil properties under the low-temperature arid climatic conditions. Table 2 presents the soil calcium carbonate content of different land-use types.

Table 2. Soil calcium carbonate content of different land-use types

\begin{tabular}{cccc}
\hline Content, $\%$ & GL, $10000 \mathrm{mu}$ & FL, $10000 \mathrm{mu}$ & CL, $10000 \mathrm{mu}$ \\
\hline $1.0-3.0$ & 2448.82 & 0 & 0 \\
$3.0-5.0$ & 30.89 & 0 & 0.4818 \\
$5.0-15.0$ & 1113.00 & 50.51 & 4.6983 \\
\hline
\end{tabular}

According to the measured data, the average soil calcium carbonate content of the county was $2.994 \%$, and the rangeability was from $1.768 \%$ to $10.297 \%$. It can be seen that soil calcium carbonate contents of CL and FL soils were greater than that of GL soil. The influence of soil calcium carbonate on the plant growth was complementary with that of soil $\mathrm{pH}$. It affected the validity of phosphorus, molybdenum, iron and other microelements, leading to the nutrient deficiency phenomenon. In addition, it had a great impact on the growth of woods and the composition of pasture community.

Soil cation exchange capacity. Soil cation exchange capacity (CEC) is defined as the amount of cations adsorbed by $100 \mathrm{~g}$ soil, whose unit is me/ $100 \mathrm{~g}$ soil. CEC is an important symbol of fertilizer-conserving capacity. Generally, it is considered the fertilizer-conserving capacity is poor when the CEC is less than 10, and the fertilizer-conserving capacity is strong when the CEC is more than 10. The soil cation exchange capacity of land-use type was shown in Table 3.

Table 3. The soil cation exchange capacity of different land-use types

\begin{tabular}{llll}
\hline CEC, me/100g soil & GL, $10000 \mathrm{mu}$ & FL, $10000 \mathrm{mu}$ & CL, $10000 \mathrm{mu}$ \\
\hline$<10$ & 0 & 0 & 0.0623 \\
$10-20$ & 2808.44 & 0 & 3.623 \\
$20-30$ & 226.63 & 50.51 & 1.4948 \\
$>30$ & 557.64 & 0 & 0 \\
\hline
\end{tabular}

The CEC of GL soil was greater than that of CL, and the CEC of the whole FL soil was more than 20. The most serious factor affected the CEC was the soil organic matter. The more the soil organic matter was, the greater the CEC was. The correlation coefficient of soil cation exchange capacity and soil organic matter was 0.7552 , reaching the extremely significant level.

Soil organic matter. Soil organic matter contains a variety of nutrients, which is an important part of soil quality. Soil organic matter has significant effects on the physicochemical properties and fertilizer-conserving capacity. In accordance with the classification standard of soil nutrients, the soil organic matter of the county is divided into four levels, namely, I $(>4 \%$; I1, 20-30\%, I2, 10-20\%, I3, $4-10 \%)$, II (3-4\%), III (2-3\%) and IV (1-2\%).

Table 4. The soil organic matter of different land-use types

\begin{tabular}{llll}
\hline Level & GL, $10000 \mathrm{mu}$ & FL, $10000 \mathrm{mu}$ & CL, $10000 \mathrm{mu}$ \\
\hline I1 & 557.64 & 0 & 0 \\
I2 & 339.99 & 0 & 0 \\
I3 & 2331.20 & 50.51 & 1.6213 \\
II & 0 & 0 & 1.1396 \\
III & 0 & 0 & 2.3932 \\
IV & 363.88 & 0 & 0.0269 \\
\hline
\end{tabular}

The average organic matter content of the county was $10.76 \%$, and the amplitude was from $1.44 \%$ to $29.45 \%$. There existed substantial differences among the land-use types. Overall, the order of soil organic matter content was GL $>$ FL $>$ CL. Soil organic matter was subject to microbe. However, the 
microbial activity was determined by the soil temperature and ventilation conditions. During the winter and spring seasons, the soil temperature was below $2{ }^{\circ} \mathrm{C}$. With the rising of temperature and the arrival of rainy season, the soil microbial activity was becoming enhancement. However, due to the barrier and rich water holding of the divot (natural moisture exceeded 90\%), the soil ventilation was extremely poor. Thus, the decomposition of organic matter by microbe was slowed down, resulting in the low mineralization and great accumulation of organic matter.

Soil nitrogen. The total $\mathrm{N}$ referred to the total nitrogen levels, which can be divided into four grades, namely, I $(>0.2 \%$; I1 $>0.8 \%, \mathrm{I} 2,0.5-0.8 \%, \mathrm{I} 3,0.2-0.5 \%)$, II $(0.15-0.2 \%)$, III $(0.1-0.15 \%)$ and IV $(0.075-0.1 \%)$. Available nitrogen (or alkali solution nitrogen) meant the nitrogen can be directly absorbed by the plant. It also divided into four grades, that was I $(>150 \mathrm{ppm}$; I1, > 600ppm, I2, 300-600ppm, I3, 150-300ppm), II (120-150ppm), III (90-120ppm) and IV (60-90ppm). The total nitrogen and available nitrogen were listed in Table 5 and Table 6 , respectively.

Table 5. The total nitrogen of different land-use types

\begin{tabular}{llll}
\hline Level & GL, $10000 \mathrm{mu}$ & FL, $10000 \mathrm{mu}$ & CL, $10000 \mathrm{mu}$ \\
\hline I1 & 749.22 & 0 & 0 \\
I2 & 185.55 & 50.51 & 0.0113 \\
I3 & 2294.06 & 0 & 2.7496 \\
II & 0 & 0 & 1.89 \\
III & 363.88 & 0 & 0.5032 \\
IV & 0 & 0 & 0.026 \\
\hline \multicolumn{4}{c}{ Table 6. The available nitrogen of different land-use types } \\
\hline Level & GL, 10000 mu & FL, 10000 mu & CL, 10000 mu \\
\hline I1 & 749.22 & 0 & 0 \\
I2 & 148.40 & 50.51 & 0.0113 \\
I3 & 2331.21 & 0 & 1.2217 \\
II & 0 & 0 & 2.2492 \\
III & 0 & 0 & 1.6719 \\
IV & 363.88 & 0 & 0.026
\end{tabular}

The average total nitrogen content of the county was $0.49 \%$, and the amplitude was $0.111-1.265 \%$. As seen in Table 5, the total nitrogen of GL soil was mainly at the I3 level, and the total nitrogen of FL soil was greater than that of CL soil. The average available nitrogen of the county was $335 \mathrm{ppm}$, and the amplitude was $85-873 \mathrm{ppm}$. The mutative trend of the available nitrogen was consistent with total nitrogen. According to the analysis, the correlation coefficient was 0.9199 , reaching the extremely significant level. The practice proved that the optimal nitrogen fertilizer content of the GL soil was 5-6 $\mathrm{kg} / \mathrm{mu}$, and it had a positive effect on improving the grass quality.

Soil phosphorus. Soil phosphorus included the forms of total phosphorus and available phosphorus. The total phosphorus and available phosphorus were listed in Table 7 and Table 8, respectively.

Table7. The total phosphorus of different land-use types

\begin{tabular}{llll}
\hline Total phosphorus, $\%$ & GL, $10000 \mathrm{mu}$ & FL, $10000 \mathrm{mu}$ & CL, $10000 \mathrm{mu}$ \\
\hline$>0.1$ & 316.9 & 50.51 & 2.1913 \\
$0.07-0.1$ & 1798.9 & 0 & 2.7716 \\
$0.04-0.07$ & 1113.03 & 0 & 0.2172 \\
$<0.04$ & 363.88 & 0 & 0 \\
\hline
\end{tabular}

Table 8. The available phosphorus of different land-use types

\begin{tabular}{llll}
\hline Available phosphorus, ppm & GL, $10000 \mathrm{mu}$ & FL, $10000 \mathrm{mu}$ & CL, $10000 \mathrm{mu}$ \\
\hline $20-40$ & 23.66 & 0 & 0.0113 \\
$10-20$ & 557.63 & 0 & 0.4358 \\
$5-10$ & 2647.54 & 50.51 & 2.5303 \\
$3-5$ & 363.88 & 0 & 2.1145 \\
$<3$ & 0 & 0 & 0.0882 \\
\hline
\end{tabular}

The average total phosphorus of the county was $0.1806 \%$, and the amplitude was from $0.07 \%$ to $0.575 \%$. As seen in Table 5, overall, the order of soil total phosphorus was CL $>$ FL $>$ GL. In addition, the average available phosphorus of the county was $8 \mathrm{ppm}$, and the amplitude was from $2.9 \mathrm{ppm}$ to 
25ppm. As seen in Table 6, overall, the order of soil available phosphorus was GL $>$ FL $>$ CL. The soil total phosphorus had little effect on the level of available phosphorus. According to the soil conditions and production levels, the degree of abundance or shortage of soil available phosphorus can be classified to rich $(>15 \mathrm{ppm})$, relative rich (10-15ppm), medium (7-10ppm), relative poor $(5-7 \mathrm{ppm})$ and poor $(<5 \mathrm{ppm})$. As presented in Table 8 , about $45 \%$ soil of the county was lack of phosphorus. So, more attention should be paid to apply phosphate fertilizer.

Soil Potassium. Soil potassium included the forms of total potassium and available potassium. The total potassium and available potassium were presented in Table 9 and Table 10, respectively.

Table 9. The total potassium of different land-use types

\begin{tabular}{llll}
\hline Total potassium, $\%$ & GL, $10000 \mathrm{mu}$ & FL, $10000 \mathrm{mu}$ & CL, $10000 \mathrm{mu}$ \\
\hline$>2.0$ & 0 & 50.51 & 4.2857 \\
$1.5-2.0$ & 2959.26 & 0 & 0.8944 \\
$1-1.5$ & 633.45 & 0 & 0 \\
\hline
\end{tabular}

Table10. The available potassium of different land-use types

\begin{tabular}{llll}
\hline Available potassium, ppm & GL, $10000 \mathrm{mu}$ & FL, $10000 \mathrm{mu}$ & $\mathrm{CL}, 10000 \mathrm{mu}$ \\
\hline$>200$ & 192.37 & 0 & 5.0391 \\
$150-200$ & 987.22 & 0 & 0.1151 \\
$100-150$ & 222.45 & 0 & 0 \\
$50-100$ & 1663.91 & 50.51 & 0.0259 \\
$<50$ & 526.76 & 0 & 0 \\
\hline
\end{tabular}

The average total potassium content was $2.08 \%$, and the amplitude was $1.685-2.52 \%$. Overall, the order of soil total potassium was $\mathrm{CL}>\mathrm{FL}>\mathrm{GL}$. In addition, the average available potassium content was $99 \mathrm{ppm}$, and the amplitude was $48-216 \mathrm{ppm}$. On the whole, the order of soil available potassium was $\mathrm{CL}>\mathrm{GL}>\mathrm{FL}$. According to the analysis, there existed a negative correlation between the total potassium and available potassium, and the correlation coefficient was -0.312 . The results demonstrated that approximately $15 \%$ soil of the county (basically GL soil) was lack of potassium, and it need not to fertilize potassium in other land-use type soils (CL, FL soil).

Soil microelements. Microelement was a necessity for normal growth of plants. The inadequate supply of microelements in soil would lead to the decrease of pasture yield and quality, while the excess microelements would result in poisoning of plants and livestock then affecting the pasture production and livestock health. A series of microelements (boron, copper, zinc, iron, manganese) was measured, and the results are shown in Table 11.

Table 11. The microelement of Shiqu County soil

\begin{tabular}{llllll}
\hline Item & $\mathrm{B}[\mathrm{ppm}]$ & $\mathrm{Cu}[\mathrm{ppm}]$ & $\mathrm{Zn}[\mathrm{ppm}]$ & $\mathrm{Fe}[\mathrm{ppm}]$ & $\mathrm{Mg}[\mathrm{ppm}]$ \\
\hline Average content & 48.83 & 11.79 & 91.93 & 30.9 & 517 \\
National average & 64 & 22 & 100 & 38 & 710 \\
Available content & 0.29 & 0.985 & 0.45 & 31.12 & 11.29 \\
Critical value & 0.5 & 0.2 & 1.0 & 7.0 & 7.0 \\
\hline
\end{tabular}

The average content of microelements in Shiqu County soil was less than the national average value. The available content of B and $\mathrm{Zn}$ can not reach the critical value. These indicated that the Shiqu County soil should fertilize microelements to improve the soil fertility. The availability of soil microelements was closely related to the soil $\mathrm{pH}$ and lime. The GL soil was slightly alkaline and high lime-content, so that the availability of microelements in GL soil was more likely to be impacted.

SOI for different land-use types. The SQI reflects the relative value of soil quality of different land-use types. The $\mathrm{Q}_{i}$ values for each indicator were computed by Equation 2 and Equation 3. Table 12 shows the results of the soil quality principal component analysis of different land-use types.

Table 12. Soil quality principal component analysis of different land-use types

\begin{tabular}{llllllllll}
\hline Item & 1 & 2 & 3 & 4 & 5 & 6 & 7 & 8 & 9 \\
\hline Percent of variance & 74.3 & 9.50 & 7.50 & 5.81 & 2.63 & 0.27 & 0 & 0 & 0 \\
Cumulative percentage & 74.3 & 83.8 & 91.3 & 97.1 & 99.73 & 100 & 100 & 100 & 100 \\
Capacity & 0.12 & 0.13 & 0.13 & 0.1 & 0.15 & 0.14 & 0.13 & 0.12 & 0.14 \\
Weight & 0.1 & 0.12 & 0.11 & 0.09 & 0.13 & 0.12 & 0.11 & 0.1 & 0.12 \\
\hline
\end{tabular}


The first component score gave a cumulative percentage of $74.3 \%$, which was sufficient to explain soil quality variations among land uses. Hence, the $\mathrm{W}_{\mathrm{i}}$ was computed in accordance with capacity of first principal component analysis. The weight of the soil quality indicator reflected the relative importance of each indicator in explaining soil quality. The SQI of different land-use types was calculated according to Equation 1. The SQI of different land-use types was in order of GL (73.2\%)> FL $(62.2 \%)>$ CL $(27.1 \%)$.

\section{Conclusion}

Our objective of the present work was to survey the soil $\mathrm{pH}$, soil calcium carbonate, cation exchange capacity, organic matter, total nitrogen, total phosphorus, total potassium, available nitrogen, available phosphorus, available potassium and microelements levels of three typical land-use types (GL, FL and CL soil) in Shiqu County. Soil samples were collected from depths of $0-20 \mathrm{~cm}$ and $20-40 \mathrm{~cm}$. The soil quality of different land-use types was evaluated by SQI. The results indicated the soil fertility of different land-use types displayed significant differences, and the whole soil should be applied microelements to improve the soil fertility. In addition, the SQI of different land-use types was in order of GL $(73.2 \%)>$ FL $(62.2 \%)>$ CL $(27.1 \%)$.

\section{Acknowledgements}

This work was financially supported by State Ethnic Affairs Commission scientific research project (14SCZ009).

\section{References}

[1] Yin, G., D. Tian, X. Fang, and Y. Hong. Effects of land use types on soil quality of the hilly area in central Hunan province. Scientia Silvae Sinicae ,2008,44: 9-15.

[2] Coll, P., E.L. Cadre, E. Blanchart, P. Hisinger, and C. Villenave. Organic viticulture and soil quality: A long-term study in Southern France. Applied Soil Ecology,2011,50: 37-44.

[3] Awasthi, K.D., B.R. Singh, and B.K. Sitaula. 2005. Profile carbon and nutrient levels and management effect on soil quality indicators in the Mardi watershed of Nepal. Acta Agriculturae Scandinavica Section B-Soil and Plant 55: 192-204.

[4] Girmay, G., and B.R. Singh. Changes in soil organic carbon stocks and soil quality: Land-use system effects in northern Ethiopia. Acta Agriculturae Scandinavica, Section B-Soil and Plant Science,2012, 62: 519-530.

[5] Butkutè, B., and A. Šlepetienè. Application of near infrared reflectance spectroscopy for the assessment of soil quality in a long-term pasture. Communications in Soil Science and Plant Analysis ,2006,37: 2389-2409.

[6] Li, X., H. Tang, Y. Tang, and X. Zhang. Effects of land use on soil quality in Huailai basin, Hebei province. Journal of Soil and Water Conservation,2004,18: 103-107.

[7] Fu, B.J., S.L. Liu, L.D. Chen, Y.H. Lu, and J. Qiu. Soil quality regime in relation to land cover and slope position across a highly modified slope landscape. Ecological Research,2004, 19: 111-118. 